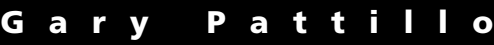
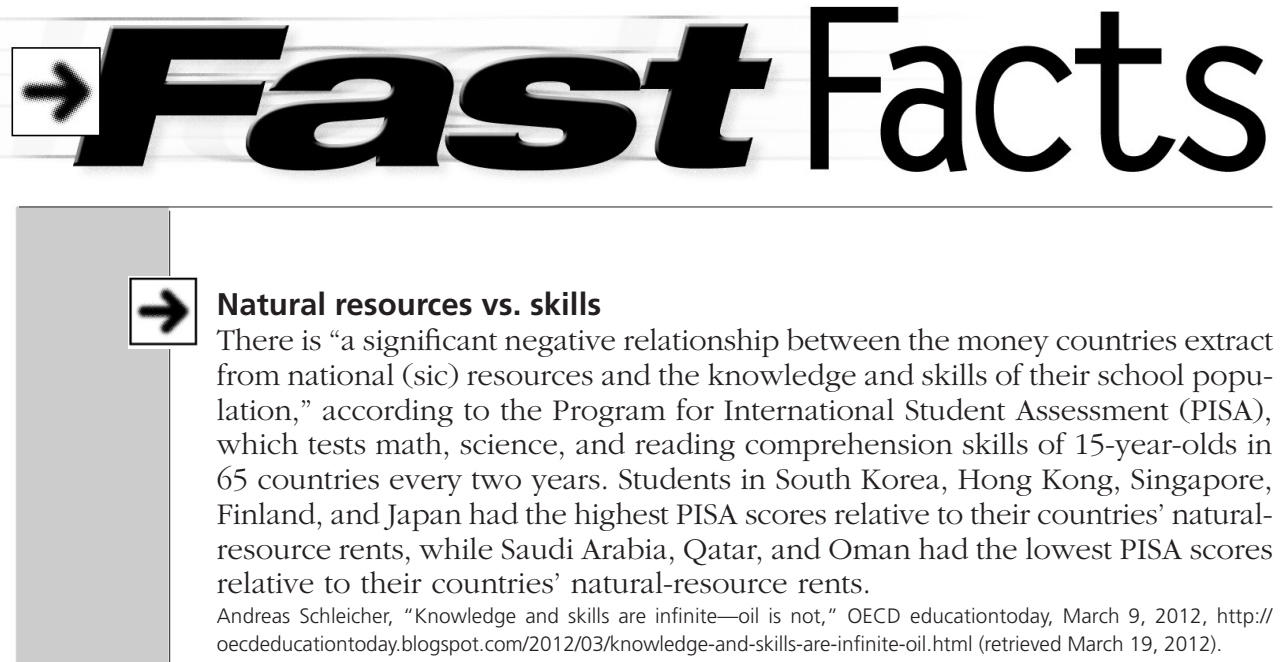

\section{Reading time}

According to a Pew Internet Libraries study, 30 percent of those "who read e-content say they now spend more time reading." Meanwhile, studies show that reading from paper is up to 30 percent faster than reading from a screen. Lee Rainie, Kathryn Zickuhr, Kristen Purcell, Mary Madden, and Joanna Brenner, "The rise of e-reading, " Pew Internet \& American Life Project, April 5, 2012, http://libraries.pewinternet.org/2012/04/04/the-rise-of-e-reading (retrieved April 8, 2012).

Panayiotis Zaphiris and H. Kurniawan, 2001, “Effects of information layout on reading speed: Differences between paper and monitor presentation," Human Factors and Ergonomics Society Annual Meeting Proceedings 45 (15): 1210-, www. soi.city.ac.uk/ zaphiri/Papers/hfes2001_reading.pdf (retrieved April 8, 2012).

\section{Banned books}

These are the ten most frequently challenged library books of 2011:

1) $t t y l ; t t f n ; l 8 r, g 8 r$ (series), by Lauren Myracle

2) The Color of Earth (series), by Kim Dong Hwa

3) The Hunger Games trilogy, by Suzanne Collins

4) My Mom's Having A Baby! A Kid's Month-by-Month Guide to Pregnancy, by Dori Hillestad Butler

5) The Absolutely True Diary of a Part-Time Indian, by Sherman Alexie

6) Alice (series), by Phyllis Reynolds Naylor

7) Brave New World, by Aldous Huxley

8) What My Mother Doesn't Know, by Sonya Sones

9) Gossip Girl (series), by Cecily Von Ziegesar

10) To Kill a Mockingbird, by Harper Lee

"2012 State of America's Libraries," American Libraries Special Issue, ALA, www.ala.org/news/mediapresscenter /americaslibraries/soal2012 (retrieved April 10, 2012).

\section{Free concert recordings}

The Internet Archive's live music library, etree.org, hit a milestone recently: 100,000 free concert recordings from more than 5,200 bands. The concerts have been downloaded or listened to almost 8 million times. The total data space for the live music archive is now 112 trillion bytes (112TB).

"Sharing Works: 100,000 concert recordings for free," Internet Archive Blogs, March 27, 2012, http://blog.archive. org/2012/03/27/sharing-works-100000-concert-recordings-for-free (retrieved April 11, 2012).

Gary Pattillo is reference librarian at the University of North Carolina-Chapel Hill, e-mail: pattillo@email. unc.edu 